\title{
O Pacto Nacional Pela Alfabetização na Idade Certa: Reflexões Sobre a Formação Docente
}

\author{
The National Pact for Literacy at the Right Age: Reflections on Teacher Education
}

\author{
Frairon César Gomes Almeida*a; Angélica Vier Munhoz ${ }^{\text {ab }}$ \\ ${ }^{a}$ Universidade do Vale do Taquari, Programa de Pós-Graduação Stricto Sensu em Ensino. RS, Brasil. \\ bPrograma de Pós-Graduação Stricto Sensu em Ensino de Ciências Exatas, RS, Brasil. \\ *E-mail: frairon.almeida@universo.univates.br
}

\begin{abstract}
Resumo
O presente trabalho apresenta uma análise reflexiva do Programa Federal, Pacto Nacional Pela Alfabetização na Idade Certa - PNAIC, na formação docente. Trata-se de uma pesquisa que surge a partir da seguinte problemática: o processo formativo oriundo do PNAIC tem contribuído para práticas diferenciadas de professores do ciclo de alfabetização? Qual a importância dessa qualificação profissional (PNAIC) para a formação docente? Assim, quanto aos procedimentos metodológicos a pesquisa é de abordagem qualitativa, quanto aos fins é exploratória e quanto aos meios bibliográfica, fundamentada, principalmente, nos documentos legais que regulamentam o Programa, além de autores tais como: Vygotsky (1989), Ferreiro e Teberosky (1984), Tardif (2012) e Nóvoa (1992), entre outros. Embora o PNAIC seja fundamentado em quatro eixos - formação continuada de professores; materiais didáticos e pedagógicos; avaliação; gestão, controle social e mobilização - a presente investigação tomou como foco principal o eixo da formação de professores, para os quais os demais se direcionam. Assim, destacamse no Programa: a ênfase do trabalho do professor a partir de uma perspectiva reflexiva; as propostas de ensino centradas em um material pedagógico diversificado e lúdico; a importância da heterogeneidade de saberes. Por fim, nota-se, que o PNAIC enquanto Política Pública contribuiu significativamente no que diz respeito a repensar as práticas do professor alfabetizador visto que trouxe em pauta, temáticas pouco exploradas e até mesmo desconhecidas por muitos profissionais. Entretanto, também foi possível perceber as fragilidades do Programa, o que decorre do fato de ser um Programa Federal, sujeito às decisões políticas e econômicas.
\end{abstract}

Palavras-chave: Educação Básica. Alfabetização. Formação de Professores.

\begin{abstract}
The following article presents an analysis on the Federal Program, National Pact for the Literacy at the Right Age - PNAIC, teacher training. It is a research that arises from the following problem: has the formative process coming from PNAIC contributed to differentiated practices of teachers of the literacy cycle? How important is this professional qualification (PNAIC) for teacher education? Thus, as for the methodological procedures the research is qualitative approach, the ends are exploratory and the bibliographic means, based mainly on the legal documents that regulate the Program, besides authors such as: Vygotsky (1989), Ferreiro and Teberosky (1984), Tardif (2012) and Nóvoa (1992), among others. Although PNAIC is based on four axes - continuing teacher education; didactic and pedagogical materials; evaluation; management, social control and mobilization - this research has focused on the axis of teacher education to which the others are directed. Thus, the following stand out in the Program: the emphasis of the teacher's work from a reflective perspective; teaching proposals centered on a diversified and playful pedagogical material; the importance of knowledge heterogeneity. Finally, it should be noted that the PNAIC as a Public Policy contributed significantly to rethink the practices of the literacy teacher as it brought to the agenda, themes little explored and even unknown to many professionals. However, it was also possible to perceive the weaknesses of the Program, which stems from the fact that it is a Federal Program, subject to political and economic decisions.
\end{abstract}

Keywords: Basic education. Literacy. Teacher training.

\section{Introdução}

O Pacto Nacional Pela Alfabetização na Idade Certa PNAIC é uma Política Pública Educacional articulada com a formação de professores, gestão dos processos, materiais, avaliação e financiamento, cuja finalidade é garantir a consolidação da alfabetização até o terceiro ano do Ensino Fundamental, o que corresponde aos oito anos de idade da criança. Trata-se de um programa criado no ano de 2012, como uma continuidade do programa Pró-Letramento (política que antecede ao PNAIC), com as devidas adaptações e modificações.

A problemática propulsora da pesquisa surgiu a partir da seguinte inquietação: o processo formativo oriundo do PNAIC tem contribuído para práticas diferenciadas de professores do ciclo de alfabetização? Qual a importância dessa qualificação profissional (PNAIC) para a formação docente?

No concernente aos objetivos, a pesquisa propõe quanto ao Objetivo Geral: Analisar as implicações do Programa Federal PNAIC para a formação docente. Em relação aos Objetivos Específicos busca-se: Investigar se o Programa Federal PNAIC tem contribuído para práticas pedagógicas diferenciadas e instigadoras do grupo de professores alfabetizadores do Ciclo de Alfabetização e Identificar os principais entraves do Programa Federal PNAIC para a formação dos professores participantes da investigação. 


\section{Desenvolvimento}

\subsection{Metodologia}

Trata-se de uma pesquisa de natureza aplicada com abordagem qualitativa, que de acordo com Vergara (2009) trata-se de ser aplicada devido à necessidade de resolver problemas e também pela curiosidade do pesquisador. Quanto aos objetivos a pesquisa é de caráter exploratório, e em relação aos procedimentos técnicos é um estudo bibliográfico. Assim, o tema pesquisado é atual e de grande relevância para o meio acadêmico, e contribuirá como mais uma fonte de consulta acerca do tema.

\subsection{Políticas Públicas Educacionais - o contexto do PNAIC}

A proposta trazida pelo Pacto Nacional pela Alfabetização na Idade Certa - PNAIC vem sendo formulada desde 2008, a partir de uma perspectiva de renovação curricular, na qual destaca-se, principalmente, a ampliação do Ensino Fundamental para nove anos, trazendo mudanças na estrutura da Educação Básica, sobretudo o ciclo inicial de alfabetização. Em decorrência dos altos índices de analfabetismo funcional apresentados no contexto brasileiro, erradicar essa realidade é um desafio já assinalado pelo próprio Plano Nacional de Educação - PNE (2011 a 2020), cuja meta é consolidar a alfabetização de todas as crianças até, no máximo, oitos anos de idade ou até o final do terceiro ano do Ensino Fundamental.

Se estabelecem como estratégias fomentar a organização do ciclo de alfabetização com duração de três anos, aplicar exames com intuito de verificar o nível de alfabetização dos alunos, diversificar os métodos e propostas pedagógicas, apoiar a alfabetização de crianças indígenas e fomentar o desenvolvimento de tecnologias educacionais (BRASIL, 2015, p. 12).

Com base nessa conjuntura de estratégias e metas traçadas pelo PNE, designou-se o Programa Federal Pacto Nacional pela Alfabetização na Idade Certa - PNAIC, originado no ano de 2012 cuja principal meta seria de alfabetizar as crianças até o final do Terceiro Ano do Ensino Fundamental correspondente aos oito anos de idade. Os 26 estados, Distrito Federal e 5.421 municípios fizeram a adesão a essa iniciativa do Ministério da Educação. Essa política, direcionada para a formação continuada do professor alfabetizador foi uma articulação entre MEC, PNLD, FNDE e PAR.

Não há como considerarmos a construção do PNAIC sem entendermos a contribuição de tantas outras políticas que diretamente ou indiretamente nela interferiram (BRASIL, 2015, p. 13). Nos momentos que antecederam a efetivação ao PNAIC, o MEC buscava novos rumos que proporcionassem uma melhoria na qualidade da educação pública, cujo foco era o processo da alfabetização da criança, partindo da premissa de uma melhor formação e valorização dos professores.

O principal eixo do programa é a Formação de Professores, para quais os demais se direcionam. A formação ofertada por meio do PNAIC é designada aos Professores Alfabetizadores, ou seja, aqueles que prestam seus trabalhos em turmas de $1^{\circ}$, $2^{\circ}, 3^{\circ}$ Ano ou Turmas Multisseriadas no ciclo de alfabetização, assim como os Orientadores de Estudo. Os Orientadores de Estudos possuem uma formação na modalidade semipresencial, tendo uma formação de 200 horas de curso, que é distribuída ao longo do ano.

Com o avanço da história os programas de formação continuada direcionados aos professores alfabetizadores foram muitos. Em várias situações os Estados e Municípios também possuíam seus próprios projetos ou programas cuja viabilidade seria de superar os problemas identificados na alfabetização. Em nível nacional sob instituição do MEC, no período de 1999 a 2014, os programas de formação direcionados aos professores alfabetizadores da rede pública de ensino foram:,

Quadro 1 - Programas de Formação Continuada para Professores Alfabetizadores: Período 1999-2014

\begin{tabular}{|c|l|}
\hline Ano & \multicolumn{1}{|c|}{ Formação Continuada } \\
\hline $\mathbf{1 9 9 9}$ & Programa Parâmetros em Ação \\
\hline $\mathbf{2 0 0 1}$ & $\begin{array}{l}\text { Programa de Formação de Professores } \\
\text { Alfabetizadores (PROFA) }\end{array}$ \\
\hline $\mathbf{2 0 0 5}$ & $\begin{array}{l}\text { Pró-Letramento: Mobilização pela qualidade da } \\
\text { educação }\end{array}$ \\
\hline $\mathbf{2 0 0 9}$ & Programa de Apoio a Leitura e Escrita (PRALER) \\
\hline $\mathbf{2 0 1 2}$ & $\begin{array}{l}\text { Formação no Pacto Nacional pela Alfabetização na } \\
\text { Idade Certa (PNAIC) }\end{array}$ \\
\hline
\end{tabular}

Fonte: Dados da pesquisa.

Na composição do curso ofertado pelo programa PróLetramento, as universidades que compõem a Rede de Formação se responsabilizam pelo desenvolvimento e produção dos materiais na área de Alfabetização e Linguagem e Matemática. As demais universidades que integram o programa participam atuando na orientação aos professores tutores e nas formações, coordenação dos seminários, certificação e avaliação do curso. Desse modo, para as universidades é destinada

\subsection{A Formação Continuada dos Professores no Contexto do PNAIC}

Para efetivar a proposta, o PNAIC utiliza como uma de suas ações, a formação continuada de professores, a qual ocorre por meio de um conjunto de elementos que envolvem Referenciais Curriculares em conjunto com os demais eixos: materiais pedagógicos, avaliação externa, gestão e monitoramento das ações.

A formação continuada dos Professores Alfabetizadores do Pacto é realizada através de cursos presenciais, com a duração em média de um ou dois anos e uma carga horária anual de 120 horas, organizado por profissionais de alguma universidade pública. Esse processo formativo é mediado pelos Orientadores de Estudo, no geral, professores da rede, que primeiramente recebem um curso específico, tendo como fundamento documentos concernentes a alfabetização e letramento em língua portuguesa, matemática, ciências e 
artes. Nessa perspectiva,

a formação continuada do PNAIC tem um importante papel para o desenvolvimento do profissional docente, objetivando maiores reflexões sobre a concepção de alfabetização e letramento, principalmente no sentido de propiciar articulação entre a teoria e a prática para que as crianças desenvolvam competências leitoras e escritoras. O PNAIC tem como orientação teórica uma concepção sociocultural de alfabetização. De acordo com o caderno de apresentação do pacto, a alfabetização deve acontecer com situações planejadas envolvendo a escrita e favorecendo concomitantemente, a aprendizagem da escrita alfabética, o letramento, possibilitando que o aluno em processo alfabético, tenha acesso a textos escritos de modo que garanta sua inserção social em vários ambientes e situações de leitura e de escrita. (BRASIL, 2012, p. 12)

Desta forma, compreende-se que o processo de alfabetização se consolida não apenas por meio da capacidade que a criança tenha de ler e escrever textos, mas complementase no entendimento do universo social da criança, de suas interações na aquisição de conhecimentos do mundo cultural. O PNAIC defende a ideia de que a aprendizagem de ler e escrever exige levar em consideração as práticas sociais de leitura e escrita, percebendo que o educando é "[...] capaz de construir conhecimentos e participar de modo ativo nos diferentes espaços de interlocução, defendendo princípios e valores" (BRASIL, 2012, p. 26). Para a obtenção deste resultado é necessário que além da prática com distintos tipos de textos que estão ao meio da sociedade, essa construção também deverá ocorrer com a integração entre os diferentes componentes curriculares, como a: Matemática, Língua Portuguesa, História, Ciências, Geografia, Artes, organizados e planejados pelo professor.

Com esse entendimento, o Pacto Nacional Pela Alfabetização na Idade Certa, fundamenta-se em quatro indicadores que deverão ser considerados no desenvolvimento do fazer pedagógico do Professor Alfabetizador, que são:

1- O Sistema de Escrita Alfabético é complexo e exige um ensino sistemático e problematizador;

2- O desenvolvimento das capacidades de leitura e de produção de textos ocorre durante todo o processo de escolarização, mas deve ser iniciado logo no inicio da Educação Básica, garantindo acesso precoce a gêneros discursivos de circulação social e a situações de interação em que as crianças se reconheçam como protagonistas de suas próprias histórias;

3- Conhecimentos oriundos das diferentes áreas de conhecimento podem e devem ser apropriados pelas crianças, de modo que elas possam ouvir, falar, ler, escrever sobre temas diversos e agir na sociedade;

4- A ludicidade e o cuidado com as crianças são condições básicas nos processos de ensino e de aprendizagem. (BRASIL, 2012, p. 27).

Cabe destacar que o Programa inicia em 2013 abordando em seu princípio temáticas somente a Língua Portuguesa, principalmente, a apropriação da leitura e da escrita no ciclo de alfabetização. No ano de 2014 a formação foi ampliada contemplando a disciplina de Matemática, sempre na perspectiva do letramento. No ano de 2015 a área de estudo desse programa de formação de professor direcionou-se para a área de Ciências e Artes, isso tudo sem deixar de levar em consideração as exigências da prática docente articulada com a Língua Portuguesa e a Matemática.

De acordo com os cadernos de orientações do PNAIC, essa consciência da necessidade que tem o professor de estar procurando se aperfeiçoar sempre, a ponto de chegar ao entendimento que o ciclo da alfabetização deve ser trabalhado de forma organizada e planejada, poderá contribuir para garantir que todas as crianças brasileiras estejam alfabetizadas no final do terceiro ano do Ensino Fundamental, conforme almeja o pacto (BRASIL, 2012, p. 29).

O PNAIC defende, assim, que a formação continuada de professores é uma ação complexa e que necessita ser apoiada pelos mais distintos segmentos da sociedade. Assim, as Instituições de Ensino Superior (IES) e a Educação Básica deverão assumir o compromisso de viabilizar reflexões, assim como propor estratégias que tenha como principal objetivo a melhoria do sistema educacional brasileiro, "[...] tendo como norte que a instituição escolar é um espaço plural e, nesse sentido, a diversidade tem que ser considerada como parte da sua essência e não como algo que justifique a exclusão do aluno" (BRASIL, 2012, p.06).

Por fim, o PNAIC considera que o professor tem uma função essencial na sociedade para a compreensão e o desenvolvimento do mundo. O professor é entendido como o profissional que muito tem a contribuir para o desenvolvimento da aprendizagem e "[...] organiza um determinado conhecimento e dispõe, de uma certa maneira, de propiciar boas condições de aprendizagem" (BRASIL, 2012, p. 6).

\subsection{O Ensino e a Aprendizagem na Formação do PNAIC}

Nesta seção, buscamos dar visibilidade aos Cadernos de Alfabetização em Língua Portuguesa e Matemática do Programa de Formação Continuada PNAIC. De início, percebemos que tais Cadernos de formação, ao levar em consideração o perfil do professor e sua respectiva ideia de alfabetização, expressam também uma concepção de ensino, cujo fundamento, de acordo com as diretrizes do Programa, pode ser caracterizado como uma atividade que visa promover a aprendizagem e a autonomia no aluno, de modo a fomentar sua capacidade para julgar e compreender os fatos de maneira independente (BRASIL, 2012). Contudo, nesse mesmo documento enfatiza-se que o ensino é apenas uma iniciativa para a promoção da aprendizagem, não significando que realmente seja atingida, ou seja, nem sempre aquilo que for ensinado pelo professor, será apreendido pelo educando. (BRASIL, 2012).

De maneira geral, a proposta de ensino, por meio dos Cadernos de formação do PNAIC, é incluir a criança em um ambiente de aprendizagem, considerando a brincadeira e os jogos como um instrumento motivador na construção do conhecimento do sistema alfabético e dos conteúdos dos 
componentes curriculares.

Ao romper com a ideia de que a aprendizagem precisa ser considerada como algo muito sério e formal, a escola passa a tomar como princípio que a agitação e movimentos em torno dos jogos e brincadeiras não se opõem à construção do conhecimento escolar, desde que o professor tenha uma clara intenção pedagógica na condução dessas atividades. Alguns materiais que fazem parte do cotidiano escolar podem contribuir para essa perspectiva (BRASIL, 2012, p. 7).

A temática de ensinar por meio do uso das brincadeiras traz algumas discussões a respeito de usar a ludicidade na sala de aula como Direito de Aprendizagem e ser um instrumento de aprendizagem do Sistema de Escrita Alfabética - SEA. Desta forma, segundo o Programa, o planejamento do professor deverá incluir propostas com uso de brincadeiras e jogos que possam estimular a aprendizagem e a inclusão da criança no processo educativo. Contudo, nas discussões firmadas pelos Cadernos do PNAIC, em relação ao uso das brincadeiras ou jogos na aquisição do SEA - material do PNAIC - não é explicado o que é brincadeira ou jogo e pouco distinguem uma atividade da outra, limitando o seu conceito. Provavelmente, o material parte do princípio que o professor já tenha esse conhecimento e consequentemente possa executar atividades diferenciando uma situação da outra.

Do ponto de vista didático, as brincadeiras promovem situações em que as crianças aprendem conceitos, atitudes e desenvolvem habilidades diversas, integrando aspectos cognitivos, sociais e físicos. Podem motivar as crianças para se envolverem nas atividades e despertam seu interesse pelos conteúdos curriculares (BRASIL, 2012, p. 7).

Entretanto, para que o professor possa integrar os jogos e as brincadeiras na rotina, torna-se imprescindível analisar qual o objetivo da atividade e dos instrumentos que serão utilizados. Assim, as estratégias de ensino, que envolvem jogos e brincadeiras, deverão contemplar as necessidades do educando, sendo avaliadas permanentemente no que diz respeito ao processo do sistema de alfabetização e letramento.

Nessa perspectiva, o professor poderia propor situações diversificadas de ensino, para que, de modo lúdico, as crianças aprendessem a escrever, ler e ampliar suas referências culturais. Assim, os textos do PNAIC enfatizam que a aprendizagem pode resultar de atividades lúdicas, na medida em que "a aprendizagem se dá por construção do sujeito na interação com o outro e com o conhecimento" (BRASIL, 2012, p. 22). Essa ideia também pode ser compreendida a partir de Horn:

Quando o brincar alcança um maior espaço nas atividades desenvolvidas em sala de aula ou as atividades apoiam-se no brincar livremente, torna-se pano de fundo da rotina escolar, o que é suficiente e satisfatório para o desenvolvimento de qualquer atividade e para uma aprendizagem significativa (HORN, 2007, p. 62).

A proposta em relação ao uso da ludicidade, de acordo com os Cadernos de Alfabetização em Língua Portuguesa do PNAIC (2002), também busca contribuir de maneira efetiva para a não segregação das crianças, proporcionando a inclusão de todos (mediante suas peculiaridades), no direito à aprendizagem. Para isso, é relevante um planejamento que atenda todas as crianças, com base em suas distinções, com adaptações necessárias de acordo com suas dificuldades. Um exemplo expressivo em relação a esse ponto é trabalhado pelo eixo "Oralidade" no ensino da Língua Portuguesa. Em relação a essa questão, os Cadernos fazem menção ao professor ter cuidado e discernimento com as crianças que apresentam comprometimento em relação a fala, analisando possibilidades e garantia de condições para que estas possam sentir-se protegidas, respeitadas, seguras e desafiadas.

As brincadeiras ao serem utilizados na prática pedagógica, transformam conteúdos maçantes em atividades interessantes e prazerosas, pois com os mesmos há motivação, disciplina e interesse pelo que está sendo ensinado. Porém, o professor deve estar consciente de que os jogos ou brincadeiras pedagógicas devem ser desenvolvidos como provocação a uma aprendizagem significativa e estímulo à construção de um novo conhecimento com o desenvolvimento de novas habilidades, sendo necessário o conhecimento das particularidades do educando para a integração de todos (BRASIL, 2012, p. 23).

Cabe destacar também que em relação à aprendizagem, os Cadernos de Alfabetização em Língua Portuguesa e Matemática, assinalam o pressuposto de que a criança aprende por meio da interação, e para sustentar tal afirmação, são apresentadas ideias de Vygotsky, dentre elas a de que o "fundamental, para ocorrer a aprendizagem, é que a criança participe de situações significativas e interaja com instrumentos" (BRASIL, 2012, p. 10).

Assim, para que esses direitos de aprendizagem sejam garantidos, de acordo com a proposta do PNAIC, é necessário organizar a progressão escolar, criando um ambiente alfabetizador que favoreça a aprendizagem. Com efeito, para que essa alfabetização ocorra, é necessário que o professor reflita ativamente sobre o sistema de escrita. Logo, o professor alfabetizador deverá, segundo o Programa, desenvolver as potencialidades das crianças através de estratégias de compreensão, delimitação do que será ensinado, organização do tempo para o planejamento, de modo a favorecer as aprendizagens não alcançadas e

[...] dedicar-se a ajudar as crianças a ganhar mais fluência de leitura e desenvoltura na escrita, além de inseri-las em situações de leitura e de produção de textos mais complexas que as que elas se depararam nos anos anteriores (BRASIL, 2012, p. 19-20).

De acordo com as perspectivas elucidadas em tais Cadernos de formação (2012), o processo de aprendizagem deve estar em consonância com o processo de ensino, além de estar articulado com os conteúdos, objetivos, recursos, a fim de que o aluno aprenda por meio da interação com pessoas e instrumentos mediados pela figura do professor.

Os Cadernos de formação continuada do PNAIC correlacionam o 'ensino', o 'favorecer a aprendizagem' e os 'componentes do ensino', ressaltando, assim, os recursos pedagógicos (livros e jogos dos acervos disponibilizados pelo MEC), os conteúdos escolares, o currículo, as estratégias de ensino, o planejamento de projetos didáticos e sequências 
didáticas, o planejamento da rotina e da avaliação, a (re) organização do ensino proposto e o acompanhamento da aprendizagem com o uso de registros (BRASIL, 2012, p. 13).

Nessa perspectiva, os Cadernos de estudo do PNAIC, também afirmam que o uso dos mais diversos recursos didáticos e instrumentos para a execução de uma variedade de atividades (com relação aos componentes curriculares), favorecem a aprendizagem. Tal justificativa se dá a partir do conceito da Zona de Desenvolvimento Proximal, de Vygotsky, em meio ao quais as capacidades e os conhecimentos efetivados poderão subsidiar a construção de um novo saber. A partir das afirmações elucidadas e com base nos pressupostos que sustentam as concepções da aprendizagem, cabe a interpretação de que a proposta do PNAIC aposta na premissa de que a criança constrói seu conhecimento por meio da interação com pessoas e instrumentos que façam parte de suas vivências.

Ao abordar o desenvolvimento e a aprendizagem da criança com suas limitações, Vygotsky já defendia que as leis de desenvolvimento são iguais para todas as pessoas, destacando que o que se diferencia, no desenvolvimento humano, é o seu percurso/ inserção social. Neste sentido, a oferta de situações lúdicas, iniciada principalmente pela figura do professor, em que as crianças brincam, é favorável à aprendizagem de todas as crianças (BRASIL, 2012, p. 7).

Em síntese, o material de formação do PNAIC faz menção ao relacionamento entre o ensino e a aprendizagem, por meio do uso de diferentes recursos pedagógicos (seja ele desenvolvido pelo professor ou disponibilizados pelo MEC), estratégias de ensino, projetos didáticos, planejamento da rotina, avaliação e reflexão constante dessas ações.-

\subsection{Ensino e Aprendizagem da Leitura e Escrita na Formação do PNAIC}

Segundo o PNAIC (2012), para alfabetizar, os professores deverão priorizar uma análise e reflexão do SEA, através das atividades fonológicas e gráficas de palavras, de textos diversificados, das interações com as atividades e gêneros textuais variados, pois os mesmos proporcionam aos alfabetizadores, reflexões sobre os diversos conhecimentos, assim como instigam neles necessidades e graus distintos de saberes.

Os textos mencionados nos Cadernos de Alfabetização em Lingua Portuguesa novamente referenciam Vygotsky (1989), destacando que a criança constrói sua aprendizagem, através da interação com o meio, mediado pela cultura. Em meio a perspectiva vygotskyana, os referidos Cadernos afirmam que aprende-se por intermédio da interação, em apropriações primeiramente interpsíquica para tornarem-se intrapsíquicas.

Nesse sentido,

a mediação social é um fator muito importante nas transformações internas do desenvolvimento da criança, para isso é essencial que ela tenha contato com instrumentos e participe de situações significativas, dando sentido para os fatos ocorrentes em seu cotidiano. (BRASIL, 2012, p. 13).
Os materiais (Cadernos) também destacam os gêneros textuais, que, por se apresentarem como instrumentos culturais, presentes nas interações sociais, funcionam como referências linguísticas.

Um gênero textual usado corretamente é um fator fundamental que potencializa o processo da consciência e, particularmente, o processo de formação da criança; no entanto, por essa participação ocorrer em um espaço destinado socialmente para as novas gerações apropriarem-se da riqueza histórica e cultural humana, o ensino deve estar voltado a criar a necessidade humana de ler e escrever, enfocando a figura do professor como elemento substancial (BRASIL, 2012, p. 5).

Outro ponto básico deste programa é a questão da heterogeneidade. Os Cadernos evidenciam que a heterogeneidade de saberes deverá ser vista como algo relevante pelo professor, pois as crianças têm percursos de vida diferentes e, muitas, antes de ingressar no ambiente escolar, já tem contato com a língua escrita e com a leitura. Dessa maneira,

como cada aluno é um indivíduo diferente do outro, um ser único, que vivencia experiências extraescolares distintas, é impossível existir uma sala de aula homogênea. A heterogeneidade de conhecimentos dos alunos de uma mesma turma ou de turmas diferentes é, portanto, natural e inevitável, não devendo ser vista de maneira negativa (BRASIL, 2012, p. 6).

Cabe, portanto, à instituição escolar favorecer situações para que todas as crianças venham a se familiarizar com a leitura e escrita, garantindo, assim, o domínio da língua

$\mathrm{O}$ atendimento adequado à heterogeneidade, em nossas salas de aula, pressupõe a necessidade de ressignificação dos espaços escolares e o redimensionamento do tempo pedagógico dedicado aos estudantes. Assim, precisamos ter consciência que aquele modelo de ensino, geralmente organizado em 'séries', cada uma durando um ano letivo, tem uma lógica excludente, exatamente porque trata como iguais os diferentes, dando-lhes 'a mesma dieta' e ignorando suas necessidades específicas (BRASIL, 2012, p. 7).

Assim, ao abordarmos a questão da heterogeneidade estamos nos reportando ao fato de que na sala de aula encontramos alunos com distintos percursos de aprendizagem, os quais deverão ser assistidos pelos professores, com vistas a serem alfabetizados, conforme é preconizado pelas diretrizes do programa. Se por um lado destaca-se a necessidade de levar em conta a heterogeneidade dos percursos dos alunos, por outro, principalmente nos Cadernos de estudo direcionados ao $3^{\circ}$ Ano, aparece, de maneira enfática, uma reflexão sobre o percurso evolutivo da criança, no processo de aprendizagem do Sistema de Escrita Alfabética - SEA, tomando como base, principalmente, as contribuições dos estudos de Emilia Ferreiro e Ana Teberosky (1984). De acordo com as autoras:

A criança reconstrói a escrita, ou seja, a escrita é algo que já existe na sociedade e que ela precisa compreender. Contudo, a criança não depende apenas de um ensino formal para começar a pensar sobre a escrita. Por viver em uma sociedade letrada, a criança constrói algumas hipóteses sobre o SEA, mesmo antes de entrar na escola (FERREIRO; TEBEROSKY, 1984, p. 71). 
De modo geral, no Caderno de Alfabetização em Língua Portuguesa, o alfabeto é compreendido como um sistema notacional e não um código. Isso significa que a escrita alfabética expressa no papel os sons das partes oralizadas das palavras, levando em consideração os segmentos sonoros menores que a sílaba.

Estes Cadernos apontam para a preocupação com a consolidação da aprendizagem do SEA, considerando-a como um desenvolvimento bastante complexo, constituída por um conjunto de propriedades a serem entendidas e internalizadas na mente de uma criança, de modo que seu domínio só ocorre quanto esta consegue compreender como a escrita ocorre, criando um conjunto de hipóteses sobre o que as letras notam (registram) e de que forma elas criam essas notações (palavras escritas). Nessa medida, o material do PNAIC também afirma que o professor, como um principal articulador dessa aprendizagem, poderá criar situações que auxiliem a criança de maneira gradativa a construir essas hipóteses e consequentemente ter o domínio do Sistema de Escrita Alfabética.

Fica bem evidente que a perspectiva teórica, abordada na proposta de alfabetização do PNAIC, é de uma abordagem construtivista, tal como podemos ver abaixo:

[...] a concepção construtivista de alfabetização, inspirada em Ferreiro \& Teberosky (1984), levou a uma mudança do foco da discussão sobre a alfabetização, antes reduzida a "como ensinar", para uma melhor compreensão da construção do conhecimento pelo aluno e suas implicações para a prática educativa. A partir dessa abordagem, passou-se a questionar sobre o 'como fazer', o 'por que fazer' e o 'para que fazer', levando-se em consideração como o aluno processa o conhecimento (sobre o SEA) e como o professor pode intervir nessa ação (BRASIL, 2012, p. 9).

Assim, os Cadernos que tratam sobre a alfabetização em Língua Portuguesa deixam claro que a aprendizagem não é simplesmente um resultado perceptivo-motor ou mesmo um ato de memorizar, mas é imprescindível que a criança possa e aprenda a interagir com aspectos lógicos e conceituais da língua.

\subsection{A Avaliação Nacional da Alfabetização (ANA)}

Muito presente no cotidiano dos docentes e discentes da educação brasileira, a avaliação em larga escala já não pode ser vista como um instrumento isolado das práticas e metodologias utilizadas em sala de aula. O Sistema de Avaliação da Educação Brasileira (SAEB), surgiu no Brasil em 1990, repercutindo diferentes maneiras, tanto em termos de produções acadêmicas, quanto no funcionamento das escolas e suas respectivas práticas pedagógicas.

A partir da proposta apresentada por meio do PNAIC, o Governo Federal, mediante o Ministério da Educação, considerou que seria indispensável encontrar uma forma de aferir o resultado de todo o investimento aplicado no respectivo programa, e é nesse contexto que há o surgimento da ANA. Essa avaliação tem como público-alvo os estudantes que se encontram matriculados no $3^{\circ}$ ano do Ensino Fundamental, ou seja, na última etapa do ciclo de alfabetização, em turmas regulares das instituições públicas, sejam elas urbanas ou rurais, que apresentem no mínimo um quantitativo de 10 alunos matriculados. Após a implantação, a ANA foi aplicada nos anos 2013, 2014 e 2016. Os principais objetivos da ANA são:

i) avaliar o nível de alfabetização dos educandos no $3^{\circ}$ ano do Ensino Fundamental.

ii) produzir indicadores sobre as condições de oferta de ensino.

iii) concorrer para a melhoria da qualidade do ensino e redução das desigualdades, em consonância com as metas e políticas estabelecidas pelas diretrizes da educação nacional. (BRASIL, 2013, p. 7).

Ofertada desde os anos iniciais, a avaliação externa vem fazer parte cada vez mais cedo no mundo do discente. A exemplo da ANA, que é objeto de estudo deste tópico, há uma ênfase em observar o cuidado e a qualidade do trabalho docente em relação ao seu alunado.

Contudo, até 2013, os resultados obtidos por meio da ANA não eram utilizados com os mesmos fins da Avaliação Nacional do Rendimento Escolar (ANRESC) e da Avaliação Nacional da Educação Básica (ANEB), integrantes do SAEB, pois de ambas as avaliações (ANRESC e ANEB), eram retirados os dados necessários para o cálculo do Índice de Desenvolvimento da Educação Básica (IDEB), que viabiliza o monitoramento e cumprimento das metas propostas pelo Plano de Desenvolvimento da Educação. Uma dessas metas desse plano é atingir 6,0 pontos na média do índice do nível de qualidade educacional dos países integrantes da Organização para a Cooperação e Desenvolvimento Econômico (OCDE).

A ANA, cujo objetivo é "garantir que todos os estudantes dos sistemas públicos de ensino estejam alfabetizados, em Língua Portuguesa e em Matemática, até o final do $3^{\circ}$ ano do Ensino Fundamental" (BRASIL, 2012, p. 16), passa a integrar o SAEB, somente a partir de 2013. Por meio da Portaria N. 482/2013, há uma reinauguração do SAEB, passando a constar agora três modalidades de avaliação: ANEB, ANRESC e ANA.

Os resultados obtidos por meio da ANA ficam disponíveis por escola em um boletim, sintetizando o desempenho dos alunos, e um informativo obtido a partir de um questionário socioeconômico que visa a orientar as ações à comunidade escolar, permitindo o acompanhamento e o monitoramento dos seus respectivos trabalhos. Além disso, a ANA é acompanhada de um projeto de formação de professores, caracterizando-se como um projeto curricular.

Dessa forma, a ANA tem por finalidade aferir o nível de proficiência do educando ao término do $3^{\circ}$ ano do Ensino Fundamental, em leitura, escrita e matemática. Considera-se, conforme as diretrizes do PNAIC (2012), que proficiência é a capacidade para realizar algo, dominar certo assunto e ter aptidão em determinada área do conhecimento.

\subsection{Os Saberes Docentes e a Reflexão no Ensino do PNAIC}

O material disponibilizado pelo PNAIC em especial o 
Caderno "Formação de Professores no Pacto Nacional pela Alfabetização na Idade Certa" evidencia que o "caminho para realização de uma ação satisfatória seria, portanto, a alternância entre a prática/teoria/prática" (BRASIL, 2012, p. 13) e salienta ainda que a "atividade de análise das práticas de sala de aula constitui-se como um bom dispositivo para trabalhar a reflexão do ensino durante as formações" (ibid, p. 14). Assim, um dos pilares apontados por este programa é que a ação reflexiva do professor seja atuante e constante de forma a viabilizar uma prática que realmente atenda as necessidades do educando. Por outra via, destaca-se a importância dos professores em analisar seus gestos profissionais de modo que se enxerguem e sejam capazes de redirecionar suas práticas para situações adequadas a sua realidade.

Os discursos mencionados nos Cadernos de ensino do PNAIC não fazem uma descrição de maneira direta sobre o que deve ou não fazer, o que é proibido ou permitido em uma sala de aula de alfabetização. A proposta, segundo as diretrizes do PNAIC, é possibilitar um direcionamento em relação ao trabalho docente, indicando possibilidades pedagógicas que venham a convergir para uma prática que efetive o processo de alfabetização. Assim, segundo os Cadernos de Ensino do PNAIC (2012), o alfabetizador, fundamentado em propostas teóricas, manuais pedagógicos e livros, sugestivamente deverá interpelar o uso dessas inovações que possibilitem a notação alfabética.

No concernente aos métodos firmados pelos Cadernos de Formação a orientação é que a ação docente seja constituída de um professor que reflita sobre suas ações, enriquecendo e modificando sua prática pedagógica, garantindo a alfabetização de todas as crianças. Isso diz respeito ao modo como os professores internalizam e constroem representações e significados para suas práticas e ações docentes.

A representação inclui as práticas e os sistemas simbólicos por meio dos quais os significados são produzidos, posicionandonos como sujeitos. É por meio dos significados produzidos pelas representações que damos sentido à nossa experiência e àquilo que somos. Podemos inclusive sugerir que esses sistemas simbólicos tornam possível aquilo que somos e aquilo no qual podemos nos tornar. (BRASIL, 2012, p. 1617).

A partir do manuseio dos Cadernos de formação é possível identificar as incumbências e os elementos que são atribuições do professor, definidas como sendo os pilares da formação continuada no contexto do PNAIC. Esses mesmos pilares indicam para um professor reflexivo que a partir das situações formativas é necessário se perceber como desafiado e a (re) pensar em suas práticas de modo a mudar suas ações.

A formação no âmbito deste programa é focada na prática do professor, de modo que as singularidades do trabalho pedagógico são objetos de reflexão. Refletir, estruturar e melhorar a ação docente é, portanto, o principal objetivo da formação. (BRASIL, 2012, p. 28).

Em relação a noção de professor reflexivo, o Programa se apropria da concepção de que as transformações das práticas docentes só se efetivam na medida em que o professor amplia sua consciência sobre a própria prática, tornando uma arma de luta para quebrar a anestesia do cotidiano. (BRASIL, 2012). Também no material do PNAIC, encontramos as ideias de Pérez Gomez (2007, p. 45), ao dizer que

a reflexão é um processo de transformação de determinado material primitivo de nossa experiência (oferecido desde a história e a cultura e mediado pelas situações que vivemos) em determinados produtos (pensamentos compreensivos, compromissos, ações), uma transformação afetada por nossa tarefa concreta(nossos pensamentos sobre as relações entre o pensamento e a ação e as relações entre o indivíduo e a sociedade), utilizando determinados meios de produção (comunicação, tomada de decisões e ação. (PÉREZ GOMEZ, 2007, p. 45)

$\mathrm{Na}$ perspectiva enunciada, a reflexão torna-se uma iniciativa de grande importância no ensino. Não se limita a um caráter simplista e corriqueiro de "pensar sobre algo", mas transcende as proposições de natureza generalizante, devendo objetivar a perspectiva do professor como intelectual crítico reflexivo. No concernente à reflexividade, o Programa propõe ações que visam tratar a prática reflexiva enquanto prática social, que só se realiza em coletivos e, portanto, torna-se um estímulo à transformação das escolas em comunidades de aprendizagem (BRASIL, 2012).

Desta forma, mediante ao uso do termo "reflexão" pelos Cadernos do PNAIC o objetivo é levar o professor a se transformar e se transformarem em uma ação coletiva, onde consequentemente essas mudanças não se refiram apenas ao que eles sabem (seus conhecimentos) ou que fazem (suas ações), mas também a relação com a sua própria maneira de ser alfabetizador, construindo e reinventando a sua prática, forjando sua identidade, através de um enfoque reflexivo e auto-avaliativo.

Ainda no tocante a uma prática reflexiva, a partir das diretrizes do PNAIC, algumas considerações poderiam ser aferidas, no sentido de problematizar o quanto a oferta do programa serviu para uma prática docente mais reflexiva. Sacristán (2007) já mencionava que "o grande fracasso da formação de professores está em que a ciência que lhes damos não lhes serve para pensar". Desta forma, a partir dessa afirmação, toma-se o seguinte questionamento: O PNAIC tem contribuído para que os professores pensem e reinventem a sua prática?

\subsection{A Leitura Deleite Articulada ao Ensino}

Um dos principais alicerces do PNAIC foi a promoção do processo formativo direcionado aos professores alfabetizadores, o qual buscou proporcionar qualificação por meio de uma prática pedagógica aliada a situações cotidianas da sala de aula. A partir dessas ações formativas, os professores foram fomentados a refletirem, aprimorarem e (re) estruturarem a sua prática docente em atividades permanentes, como: projetos didáticos, sequencias didáticas, atividades de sistematização e a leitura deleite, que é o foco do tópico, aqui 
mencionado.

A leitura deleite na sala de aula é uma atividade que permite ao aluno entender que em nossa vida lemos com várias finalidades e, entre elas, fazemos a leitura só por prazer, para divertimento. A leitura deleite pode ser realizada de forma individual, em dupla, coletiva ou protocolada, com continuidade no dia seguinte, utilizando diferentes textos (CRUZ; MANZONI; SILVA, 2012, p. 175).

A proposta da leitura deleite, prevista no Programa PNAIC, parte de um espaço da sala de aula que não pode mais ser impregnado de textos que não tem relação com a vida externa, tomando um distanciamento dos usos sociais da escrita. Além disso, essa tipologia textual, proveniente de textos literários, apenas proporciona à criança o hábito de direcionar seu raciocínio na decifração das palavras, sem realizar um direcionamento da leitura que construa sentidos com essa interação textual, ficando ainda mais distante do que significa realmente o ato de ler. Para Smith (1999), a leitura é a associação do que está atrás dos olhos com o que está à frente dos olhos, pois apenas decodificar e não encontrar sentido não seria para o autor considerado como leitura.

A leitura genuína seria aquela em que depois de finalizada é capaz de gerar conhecimentos, propondo atitudes e reflexão no leitor. Assim, no processo do ensino o professor poderá permitir que a leitura seja vista como algo concreto, significativo, útil, atraente e que vá de encontro às experiências vivenciadas pelas crianças. A leitura deleite parte da premissa de que a leitura deve ser realizada pelo simples prazer de ler. Nesse sentido, a proposta consiste em, com a mediação do professor, ofertar leituras distintas para que o aluno possa se divertir, sentir prazer, mas também aprender com as leituras.

O momento da 'leitura deleite' é sempre de prazer e reflexão sobre o que é lido, sem se preocupar com a questão formal da leitura. É ler para se divertir, sentir prazer, para refletir sobre a vida. Tal prática, no entanto, não exclui as situações em que se conversa sobre os textos, pois esse momento também é de prazer, além de ser de ampliação de saberes (BRASIL, 2012, p. 49).

Ao ocorrer a inserção da leitura deleite como uma atividade permanente nas salas de alfabetização, o educando poderá perceber que nos distintos momentos do seu cotidiano a leitura se faz presente com finalidades diferentes, tais como:

- estimular a formação de leitores despertando o gosto pela leitura;

- mostrar que o ato de ler pode ser uma forma de entretimento ao mesmo tempo que ensina, informa e diverte;

- estimular a importância da preparação para o que será lido para o grande grupo;

- proporcionar o contato com diferentes gêneros textuais, autores, ilustradores e estilos diferentes de escrita;

- estimular a imaginação, criatividade e curiosidade em querer aprender;

- ampliar o repertório de leituras, tornando-os capazes de formular juízos de valor sobre os significados apreendidos, sobre a validade e adequação das ideias, comparando-as com experiências e leituras anteriores. (BRASIL, 2012, p. 51)

Conforme mencionado acima, percebe-se que são incontáveis os resultados proporcionados pela leitura deleite, por isso, torna-se instrumento inseparável na prática do ensino realizada pelo professor, principalmente na aquisição e consolidação da leitura e escrita. É relevante mencionar que embora os Cadernos de formação do PNAIC façam referência à importância do uso da leitura para deleite, os mesmos não apresentam embasamentos teórico-metodológico de como realizar a apresentação dessa leitura às crianças. Constatase que o termo faz referências apenas a uma atividade a ser aplicada em sala de aula a partir de uma concepção prévia do próprio professor. Assim, durante o processo formativo os educadores são postos a pensar sobre as possibilidades de trabalhos a partir da leitura deleite.

A leitura deleite já havia sido mencionada em programas anteriores, como por exemplo, o Pró-letramento, que ocorreu anterior ao PNAIC. Leal e Albuquerque (2010) citam que no contexto do Pró-letramento essa foi uma atividade bem aceita pelos professores que integravam o programa. "A 'leitura deleite' é o gosto pela leitura sem se cobrar nada: você conta a história, trabalha a capa, fala a biografia do autor, que a gente não tinha esse hábito, a gente falava 'ah, o autor é fulano', mas você não falava sobre ele". (LEAL; ALBUQUERQUE, 2010, p. 45).

Caracterizada pelo prazer de ler, diferentemente das demais leituras que permeiam a escola, a leitura deleite também deve fazer parte da formação do professor, que tem nessa prática, uma das mais importantes ferramentas de trabalhos, possibilitando qualificar e ampliar a sua prática docente.

A profissão docente exige certo número de saberes particulares que servem de base para a sua prática. Este repertório de saberes, próprio da profissão, não deve ser separado do conjunto de saberes que o professor, enquanto indivíduo possui, eles são inerentes a sua experiência de vida pessoal e são denominados saberes culturais e pessoais (TARDIF, 2012, p. 48).

O professor, portanto, é compreendido pelo PNAIC, não somente como um mediador da leitura, mas também como leitor em sua formação pessoal, estética e sensível, o que poderá contribuir, consequentemente, para ampliação do seu repertório de saberes.

Com efeito, a prática da leitura deleite só poderá ter sucesso se o próprio professor for o primeiro a ser fascinado pela leitura, tendo em vista que a principal prerrogativa para fazer a mediação entre a criança e o livro, é o próprio leitor. Assim, para fomentar o gosto pela leitura nos alunos, a primeira etapa caberia ao próprio professor desperta-se para esses fins.

[...] o professor é um entusiasta da leitura e comunica esse entusiasmo às crianças, existe grande possibilidade de que estas sejam seduzidas pela leitura, por conta da curiosidade sobre o que está sendo lido. É muito importante que a criança veja o professor lendo. Nos momentos em que as crianças leem silenciosamente, é interessante que o professor o faça também, de modo que o ambiente escolar seja visto como lugar agradável do exercício da leitura para ambos (BRASIL, 


\section{2, p.54).}

Frente ao que foi mencionado, o próprio PNAIC em seu primeiro ano de atuação, 2013, realizou a entrega de uma caixa de livros para leitura deleite junto a um manual orientando o seu uso. Esse material foi chamado de Acervo Complementar, cujo objetivo era dar suporte ao trabalho de ensino do professor, o qual poderia realizar, em suas aulas, leituras de uma forma mais descontraída e informal, instigando a criança a ser um assíduo leitor.

Cabe compreender de que modo esse material foi utilizado pelos professores e escolas e em que medida os mesmos auxiliaram na construção da prática alfabetizadora dos professores que fizeram parte do Programa PNAIC. Essas questões serão melhor delineadas na secção que dialoga com os professores participantes da investigação.

\section{Conclusão}

O PNAIC, de fato, foi um programa que oportunizou um olhar mais criterioso quanto à prática do professor direcionada aos Anos Iniciais do Ensino Fundamental, especificamente ao ciclo de alfabetização. Contudo, este não pode ser avaliado como totalmente eficiente e adequado, assim como, não pode ser compreendido como totalmente ineficiente. Não há dúvidas que o programa apresentou algumas variantes que, talvez, possa justificar o fato de não se ter um resultado tão auspicioso o quanto se esperava. Isso se deve, principalmente ao fato de ser um Programa Federal que fica à mercê de decisões políticas, econômicas, que nem sempre são imparciais.

Assim, como qualquer outro programa é possível elencar alguns pontos que resultaram nas suas fragilidades. Cabe, contudo, destacar que muitas destas fragilidades não ocorreram de forma isolada, já que se trata de um mesmo Programa aplicado em todo o país.

- O fato das formações terem início nos últimos meses do ano: desde a primeira etapa do PNAIC em 2013, o início do processo formativo sempre ocorria entre os meses de outubro ou novembro, causando um certo desconforto tanto pelo período como também frente aos professores contratados.

- O corte das bolsas a partir da versão 2017/2018: Em 2017 por motivo de contenção de gastos o Governo Federal cortou as bolsas destinadas aos Professores Alfabetizadores no valor de duzentos reais. Essa situação gerou uma grande discussão e muito dos professores (principalmente os efetivos) acabaram não se inscrevendo nessa etapa.

- Os materiais destinados aos cursistas: a partir da etapa 2017/2018 os cursistas passaram a não receber mais os Cadernos de Estudos. Esse material ficava disponibilizado no site do programa onde o cursista deveria fazer sua respectiva impressão. Outro fato notório é que no geral os Cadernos de Estudos quando disponibilizados de maneira física pelo Governo Federal só chegavam na reta final da etapa de estudo.

Ademais, não podemos ficar limitados a falar apenas das mazelas. A partir das leituras realizadas sobre Formação
Continuada e as intervenções feitas (observação, entrevista, rodas de conversas) constatou-se a ansiedade que os professores possuem em receber uma formação de qualidade com o objetivo de desenvolver uma prática mais direcionada a um processo de alfabetização que atendesse ao alunado.

A formação em serviço, na escola, proporciona ao professor uma reflexão de sua prática a partir da sua própria realidade profissional e do contexto do ambiente de seu trabalho. A partir dos diálogos estabelecidos entre pesquisador e o grupo de professoras ficou evidente que alguns termos chaves, como: sequência didática, leitura deleite, alfabetizar na perspectiva do letramento, ludicidade, entre outros, passaram a ter uma conotação mais expressiva na formação destes profissionais. Isso vem a demonstrar que a apropriação das formações do Pacto, pelas professoras foram direcionadas para o desenvolvimento de suas atividades de acordo com as sugestões e adequações delineadas pelo PNAIC.

Outra constatação importante obtida por meio da pesquisa realizada é que o Pacto fortaleceu ações importantes no processo de ensino e aprendizagem, principalmente no que condiz ao uso de materiais concretos e jogos na alfabetização, tanto em Língua Portuguesa como na Matemática.

Portanto, nota-se a importância que há em uma formação direcionada para o contexto da escola e na escola, espaço em que o professor, junto aos seus pares, possa dialogar, refletir, aprimorar suas práticas, partindo sempre do pressuposto de suas reflexões sobre sua própria prática, as necessidades do aluno e intencionalidade do ato de ensinar.

Contudo, entende-se que o PNAIC, por ser um Programa de abrangência nacional tem seus desafios de implementação quanto às particularidades do local, região, escola, professor, entre outros fatores. Assim, é necessário extrair aquilo que de significativo pode ser agregado à formação do profissional diante da singularidade que o permeia. Para tanto, tornase imprescindível o abandono de práticas prescritivas que delimitam propostas prontas e definidas, apontando como deverá ser desenvolvida a ação docente.

Por fim, acredita-se que o PNAIC enquanto Política Pública contribuiu significativamente no que diz respeito a repensar as práticas do professor alfabetizador visto que trouxe em pauta, temáticas pouco exploradas e até mesmo desconhecidas por muitos profissionais em serviços. Entretanto, não se pode ver este Programa como um fim em si mesmo, é necessário que todos os agentes envolvidos se proponham de maneira contínua a estudar, refletir, se engajar, a fim de construir uma prática alfabetizadora que proporcione aos alunos, aprendizagens efetivas.

\section{Referências}

BRASIL. Lei de Diretrizes e Bases da Educação Nacional. 9394/96. Estabelece as diretrizes e bases da Educação Nacional. Diário Oficial da União, Brasília, DF. 11 de ag. 1996.

BRASIL. Constituição da República Federativa do Brasil. Brasília, 1988. 
BRASIL. Decreto n. 6.094, de 24 de abril de 2007. Dispõe sobre a implementação do Plano de Metas Compromisso Todos pela Educação. Brasília, 24 abr. 2007. Disponível em: <http://www. planalto.gov.br/ccivil 03/ ato2007-2010/2007/decreto/ d6094. htm>. Acesso em: 28 out. 2018.

BRASIL. Ministério da Educação. Instituto Nacional de Estudos e Pesquisas Educacionais Anísio Teixeira (INEP). Avaliação Nacional da Alfabetização (ANA). Diretoria de Avaliação da Educação Básica. Apresentação, maio de 2013.

BRASIL. Secretaria de Educação Básica. Diretoria de Apoio à Gestão Educacional . Pacto Nacional pela Alfabetização na Idade Certa: apresentação. Brasília: MEC, SEB, 2013.

BRASIL. Secretaria de Educação Básica. Diretoria de Apoio à Gestão Educacional. Pacto Nacional pela Alfabetização na Idade Certa: manual do pacto. Brasília: MEC, SEB, 2012.

BRASIL. Secretaria de Educação Básica. Diretoria de Apoio à Gestão Educacional. Pacto Nacional Pela Alfabetização na Idade Certa. Ano 02, Unidade 08. Reflexões sobre a prática do professor no ciclo de alfabetização, progressão e continuidade das aprendizagens para a construção do conhecimento por todas as crianças. Brasília: MEC, SEB, 2012.

CRUZ, M.C.S.; MANZONI, R.M.; SILVA, A.M.P. Planejamento no ciclo de alfabetização: objetivos e estratégias para o ensino relativo ao componente curricular - Língua Portuguesa. In: BRASIL. Secretaria de Educação Básica. Diretoria de Apoio à Gestão Educacional. Pacto nacional pela alfabetização na idade certa: caderno a organização do planejamento e da rotina no ciclo de alfabetização na perspectiva do letramento: ano 2: unidade. Brasília: MEC, SEB, 2012.

FERREIRO, E.; TEBEROSKY, A. Psicogênese da língua escrita. Porto Alegre: Artmed, 1984.

HORN, C.I.. Brincar e jogar: atividades com matérias de baixo custo. Porto Alegre: Mediação, 2012.

LEAL, T.F.; ALBUQUERQUE, E.B.C. Literatura e formação de leitores na escola. In: PAIVA, A.; MACIEL, F.I.P.; COSSON R. (Coord.). Literatura: Ensino Fundamental. Brasília: MEC, 2010.

NÓVOA, António. Os professores e a sua formação. Lisboa: D. Quixote, 1992.

PÉREZ GÓMEZ, A. O pensamento prático do professor como profissional reflexivo. In: NÓVOA, A. (Coord.). Os professores e a sua formação. Lisboa: Publicações Dom Quixote/IIE, 2007.

SACRISTÁN, J.G. O currículo: uma reflexão sobre a prática. Porto Alegre: Artmed, 2007.

SMITH, F. Leitura significativa. Porto Alegre: Artes Médicas, 1999.

TARDIF, M. Saberes docentes e formação profissional. Petrópolis: Vozes, 2012.

VERGARA, S.C. Projetos e relatórios de pesquisa. São Paulo: Atlas, 2009.

VYGOTSKY, L.S. A construção do pensamento e da linguagem. São Paulo: WMF Martins Fontes, 1989. 